\title{
AUTOMATIC IDENTIFICATION OF SUBMARINE LANDFORMS USING OBJECT BASED IMAGE ANALYSIS IN THE AREA OF NORTH AEGEAN BASIN
}

\author{
Argyropoulou E. ${ }^{1}$, Argialas D. ${ }^{2}$, Nomikou P. ${ }^{3}$, Papanikolaou D. ${ }^{3}$ and \\ Dekavalla M. ${ }^{2}$ \\ ${ }^{1}$ School of Rural and Surveying Engineering, National Technical University of Athens, Greece, \\ lilyargyropoulou@gmail.com \\ ${ }^{2}$ Laboratory of Remote Sensing, Department of Surveying, School of Rural and Surveying \\ Engineering, National Technical University of Athens, Greece, argialas@gmail.com, \\ dekavalla.maria@gmail.com \\ ${ }^{3}$ Department of Geology, University of Athens, Panepistimioupoli Zografou, 15784 Athens, \\ Greece,evinom@geol.uoa.gr,dpapan@geol.uoa.gr
}

\begin{abstract}
This paper is focused on the study of the North Aegean seabed, from a Digital Seabed Elevation Model (DSEM), by employing Object Based Image Analysis (OBIA). The goal is the automatic extraction of geomorphological features based on morphological criteria, in the North Aegean Basin. A Digital Seabed Elevation Model (DSEM) of $150 \times 150$ meters resolution was employed. At first, slope gradient, profile curvature, and percentile were derived from this DSEM. Four different layers of segmentation were created in order to extract the final geomorphological classes, discontinuities, faults like and fault surface in the final segmentation of level 4. On previous levels, more geomorphological features were also classified such as continental platform and continental slope. The results were evaluated qualitatively and quantitatively, through a tectonic map which has been created manually based on the analysis of seismic profiles. The results of the comparison of the two methods were satisfactory. Thus, the developed OBIA method is considered successful.

Keywords: Digital Seabed Elevation Model, geomorphometry, faults, fault surfaces

\section{Пєрí $\eta \psi \eta$}

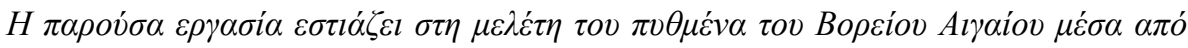

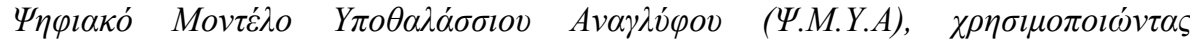

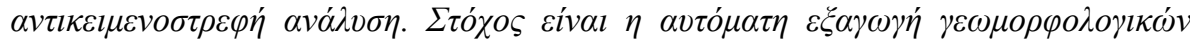

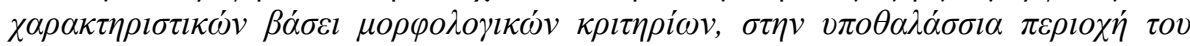

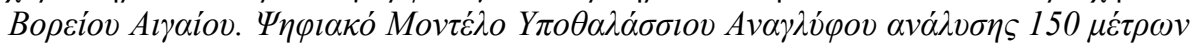

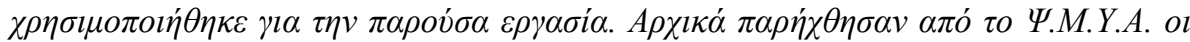

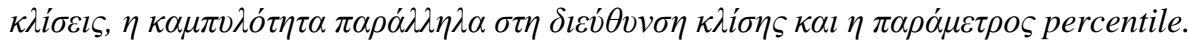

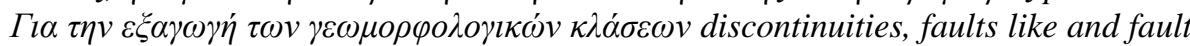

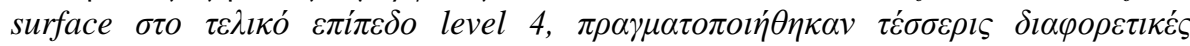

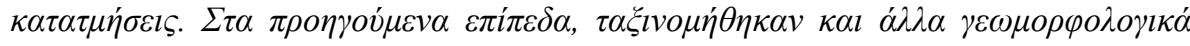

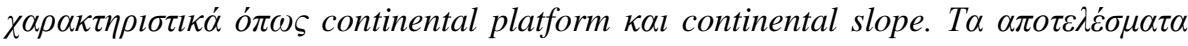

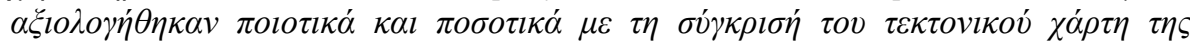




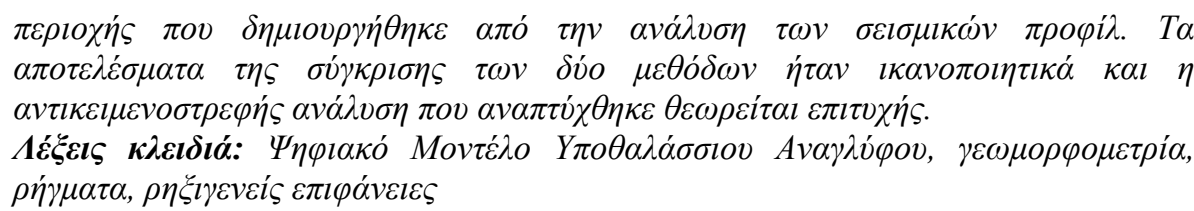

\section{Introduction}

The Aegean region is characterized by special and intense geomorphological features, both on land and offshore. This particular morphology occurs since the Hellenic Arc is on the verge of the Eurasian plate, bordering the African lithospheric plate (Le Pichon and Angelier, 1979). This fact enhances the seismicity of Greece since the undersea faults are responsible for causing major earthquakes with high magnitude (Papazachos, 1980). Mapping submarine fault surfaces, is of great importance, and in general mapping and collecting offshore data can be carried out only in situ using advanced technological instruments and in highly increased cost such as multi-sonar (multi-beam) echosounder, usually attached below an oceanographic vessel.

Morphological analysis of the seafloor is considered a rather tedious and time consuming task requiring expertise. Therefore, semi-automated or computer assisted processes are crucial in terms of economy. The present work is based on Object Based Image Analysis (OBIA) which is a method based on the idea that important semantic information necessary to interpret an image is mostly not represented in single pixels but in meaningful image objects and their mutual relations (Baatz and Schape, 1999) and has been employed for the interpretation and classification of satellite imagery and Digital Elevation Models (DEM) of the land surface (Argialas and Tzotsos, 2003). The objectives of this study were the development of an OBIA approach for extracting specific landforms through a digital seabed elevation model (resolution 150x 150 meters) of the North Aegean Basin and the investigation of the ability of this kind of analysis, in comparison to the techniques of morphotectonic analysis.

\section{Physical setting}

The North Aegean Basin is located in the northern part of the Aegean Sea behind the main active part of the Hellenic Orogenic Arc, which was formed within the convergence zone between the northward-subducting African plate and the Hellenic margin of the Eurasia plate (McKenzie, 1970, 1972; Angelier, 1979; Angelier et al., 1981). The Aegean has split a pre-existing tectonized continental crust and is also stretching in response to a general westward motion of the TurkishAnatolian continental block imposed by the southern collision of the Arabian plate in the late Miocene. Because of this specific geodynamic setting, the Aegean has been considered a "deforming microplate" bordered by the westward extension the Anatolian fault zone to the North accommodated by dextral strike slip motion and the Levantine segment of the Hellenic subduction zone. (Brunn, 1976; Angelier, 1979, 1981; Șengör, 1979; Taymaz et al., 1991; Jackson, 1994; Armijo et al., 1999; Papanikolaou et al., 2006.)

The overall basin geometry is a rectangular tetrahedron shaped by the major slope discontinuity separating the continental platform from the continental slope. The area distribution with depth shows a maximum at depths between 300 and $450 \mathrm{~m}$ along the sub-horizontal edge of the continental platform and at depths between 1000 and $1200 \mathrm{~m}$ at the basinal areas of the sub-basins. The active fault zones characterized by slope values $>20 \%$ are trending to NE-SW (N460) and NW-SE $\left(\mathrm{N} 136^{\circ}\right)$. Some secondary E-W faults are also present within the basin (Papanikolaou et al., 2002).

\section{Materials and methods}

The multi-beam bathymetric survey was carried out on the research vessel AEGAEO of the Hellenic Centre for Marine Research (HCMR) using "SEABEAM 2120" swath system. The SEABEAM 2120 is a hull-mounted system operating at $20 \mathrm{kHz}$ to work at water depths not exceeding $6000 \mathrm{~m}$, 
for which the swath width varies from about 7.5 to 1.15 times the water depth for depths of 1000$5000 \mathrm{~m}$, respectively. It has an angular coverage sector of $150^{\circ}$ with 149 beams of $1.8^{\circ}$ spaced $1^{\circ}$ apart, thus giving about 50\% overlap. Having variable swath coverage, from less than $1 \mathrm{~km}$ for depths below $300 \mathrm{~m}$ to more than $4.5 \mathrm{~km}$ for depths over $1000 \mathrm{~m}$, a total area of $11.200 \mathrm{~km}^{2}$ was mapped (Papanikolaou et al., 2002, 2006).

For the Object Based Image Analysis (OBIA) approach the eCognition 8.7 software was employed. The eCognition software (Trimble, 2011) employs a variety of algorithms in order to create objects through the segmentation process, and then to classify them based on a selected number of features.

This paper aims to identify morphotectonic and morphological features (i.e. fault surfaces, faults, discontinuities, continental platform, continental slope, basins) in the North Aegean Basin characterized by complex seabed morphology and a variety of tectonic elements. The main morphological structures of this region which will be extracted through the object based image analysis are the continental platform, the continental slope, the basins (inside the basinal area) and the morphotectonic features discontinuities, faults like and the fault surface.

\subsection{Preprocessing}

The bathymetric data generated, in the way described above, consist of a Digital Seabed Elevation Model in a .grd format. Firstly, the DSEM was transformed from WGS 84 geographic coordinate system to the Hellenic Geodetic Reference System 87, using bilinear transformation in the environment of ERMapper. In the next step, the image values were normalized in the range from 0 to 255, as the image was originally in negative elevation values (depth). In Figure 1, the areas shown in dark color, correspond to the deepest areas while those having high values of brightness, which appear lighter, correspond to rather shallow areas.

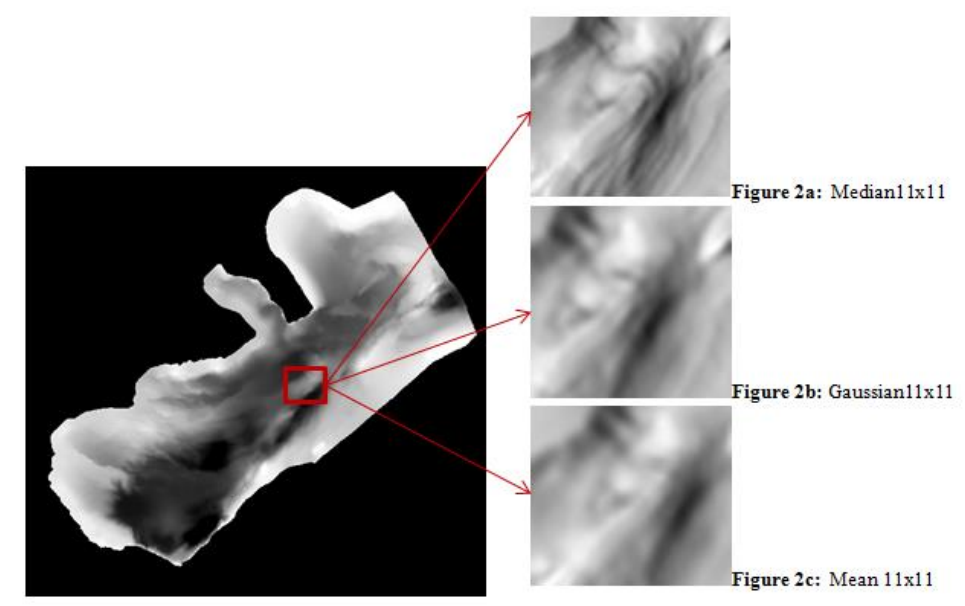

Figure 1 - Representation of the DSEM of the study area with brightness values 0-255.

It was observed that the DSEM contained noise, therefore various smoothing filters were applied in order to choose the best among the Median 11x11, Gaussian 11x11 and Mean 11x11. The results of these filters appear in Figure 1a, 1b, 1c respectively. Upon comparison, the Gaussian 11x11 filter was chosen because a mean smoothing of the whole image was achieved, compared to the other two filters, as shown in Figure 1a and 1c.

\subsection{Computation of Geomorphometric parameters from the DSEM}

In order to describe the landform classes in OBIA, one needs appropriate features. Geomorphometric processing of the DSEM provided such features, e.g slope gradient, profile curvature and percentile. To compute these features a mathematical model is required describing the surface employed. The most widely used mathematical models are those of Evans - Young (Evans, 1972; Young, 1978) and 
Zevenbergen and Thorne, 1987. For the needs of this paper the Evans-Young approach was applied through the ERMapper software.

Slope gradient reflects the maximal rate of change of elevation values. Slope gradient can be expressed in radians or degrees, but it is usual (and more practical in many fields) to reflect its values in \%, The structure of a DEM as a grid is equivalent to a raster image simulating depth values to brightness values from 0 to 255 . As mentioned above, the deepest areas correspond to low values of brightness e.g. close to zero, while the shallower to brighter ones e.g. close to 255 .

As regards the recognition of curvatures on a slope, there are four normal sections known as: profile (or vertical) curvature, tangential (or horizontal) curvature, maximal curvature and minimal curvature. The profile (or vertical) curvature and tangential (or horizontal) curvature can be used to distinguish (locally) convex and concave shapes. Concave tangential curvature indicates convergence and convex divergence of flow lines. Convex profile curvature indicates acceleration of flow and concave deceleration of flow.

Percentile calculates the area that is lower than the central point within a predetermined neighborhood, resulting in a percentile range from 0 (central point is the lowest point within a predetermined neighborhood) to 100 (central point is the highest point within a predetermined neighborhood). An advantage of the percentile usage is that the well-defined range, makes its application simple and robust (Wilson and Gallant, 2000). For the needs of this paper, many different radii of percentile were tested on the Saga GIS software, and percentile with a radius of 100 was finally chosen, for the reasons described in each class where percentile was used.

\subsection{Segmentation and classification of digital seabed elevation model (DSEM)}

The DSEM and the derived geomorphometric features slope gradient, curvatures and percentile were imported into the eCognition software. In this study, OBIA was applied through the eCognition softw are and this approach includes two basic procedures: segmentation and classification (Baatz and Scha pe, 1999). Through segmentation, the DSEM is segmented into objects. eCognition provides the algo rithm "multiresolution segmentation", with which the pixels are merged into objects taking into acco unt user set parameters such as the desirable heterogeneity, the size and the shape of the objects to be created. Different segmentation parameters can be applied creating different objects in various resolution levels of hierarchy in the same image. Subsequently, the user defines the classes of interest assigning selected attributes and their values through fuzzy membership functions to each class. The objects of the image are then classified through fuzzy logic into the selected classes, each obtaining the proper membership value to each class.

With an initial criterion of the nature and size of the objects to be exported, eventually four differe nt levels of segmentation with different scales were set, with the number of levels to follow the ord er of creation. The next step, after segmentation, was concerning the class creation, choosing and a pplying the right membership functions for each class feature independently.

\section{Results}

\section{Level 1}

Level 1 was created aiming at mapping large objects, such as continental platform, so a large scale parameter (500) was used for segmentation, while shape was set to 0.1 and compactness to 0.5 so that to obtain large compact objects (Figure 2a). Then, the continental platform(1) and not continental platform(1) were defined. As continental platform(1) is defined as a flat, shallow area of the seabed, the percentile parameter was used with a value of 100 , because the central point of each predetermined neighborhood of 100 pixels composing the continental platform, represents the highest point in it, by definition of the percentile parameter. In order to select the optimum radius of 100 pixels, many tests were made from a radius of 10 to 100 . In order continental platform(1) to be classified, a fuzzy s-shaped membership function was used on mean percentile with a radius of 100 . 
The left side of the s-shaped membership function is defined at 68.9 and the right side at 69 . Objects with lower values than the left side value of the membership function have membership value 0 , while objects with higher values than the right side value have membership value 1 . Objects with values falling within the range (left side value - right side value) of the membership function have membership values ranging from 0 to 1 .

The not continental platform(1) class was determined, with an inversion of the expression of the class continental platform(1) and it was created for further classification in lower levels. The result of this level's classification is shown on Figure $2 b$ with the corresponding legend.
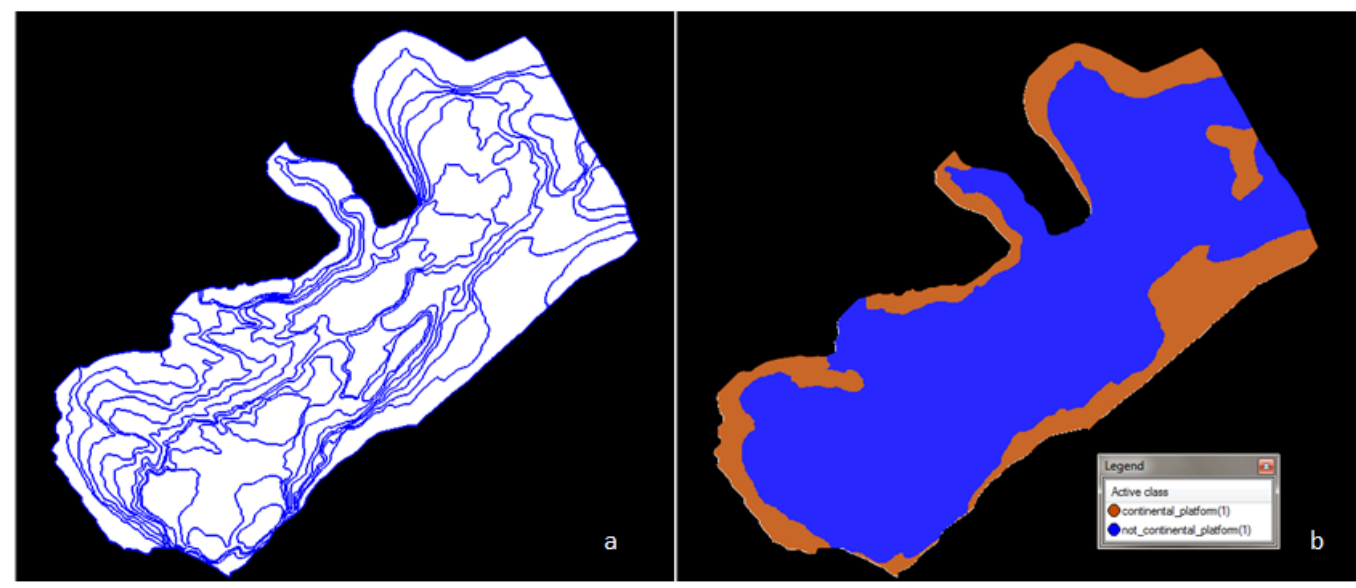

Figure 2 - a: Segmentation result of level 1 with scale parameter 500 (shape 0.1, compactness 0.5), b: The classification result of level 1.

\section{Level 2}

Level 2 aimed at defining the basins(2) of the study area. The first step was to choose the most appropriate scale for segmentation. After trial and error testing, a scale of 50 was chosen because it was the most suitable to represent the shape and the size of the various basins (Figure 3a).The shape and compactness were set to 0.4 and 0.3 corespondingly.

As regards the classification of level 2, knowing that a basic characteristic of a basin is its large depth compared with the surroundings, the mean percentile with a radius of 100, was again used, with the left side of the $\mathrm{z}$-shaped membership function at 27 and the right side at 27.0001 , where the central point of each basin is the lowest point within the neighborhood of 100 pixels. The value of 27 was chosen after trial and error testing. The second criterion for basin exctraction was, the existence of super object in not continental platform(1) of level 1, i.e. all the objects of level 2 must be included in the class of not continental platform(1). Furtheremore, in this level, another class was created by an inversion of the class basins(2) with mostly a semantic character and that was the not basins(2) class. The classification result of level 2 is shown on Figure $3 \mathrm{~b}$ with the corresponding legend.

\section{Level 3}

The objective of level 3 was the extraction of the continental slope(3) and the projection of basins(2) and continental platform(1) from level 2 and level 1, respectively, to level 3. Thus, more detailed segmentation was applied, with scale 5 , shape 0.1 and compactness 0.5 , for the determination of the exact location of continental slope, as it is a kind of landform with a linear shape, with a steep slope gradient and it has a relative border to continental platform. A part of the segmentation result is shown in Figure 4a. 

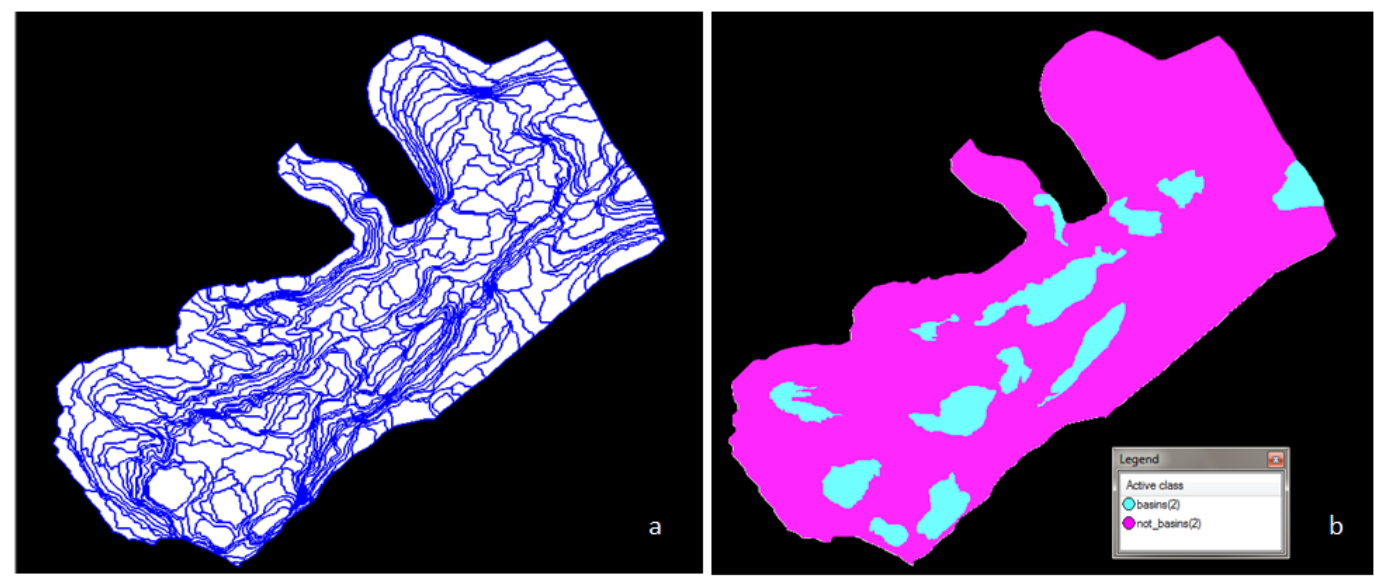

Figure 3 - a: Segmentation result of level 2 with scale parameter 50 (shape 0.4, compactness $0.3)$, b: The classification result of level 2.

In order for continental slope(3) to be defined, a spatial criterion was used, starting (by definition) that the continental slope(3) must have a relative border with the continental platform(3) more than $20 \%$ and also the mean slope must be more than 5\% taking into consideration that the continental slope (3) is a steep area where the transition from the continental platform(3) to basinal area is taking place. The result of level 3 classification is shown on Figure $4 \mathrm{~b}$.

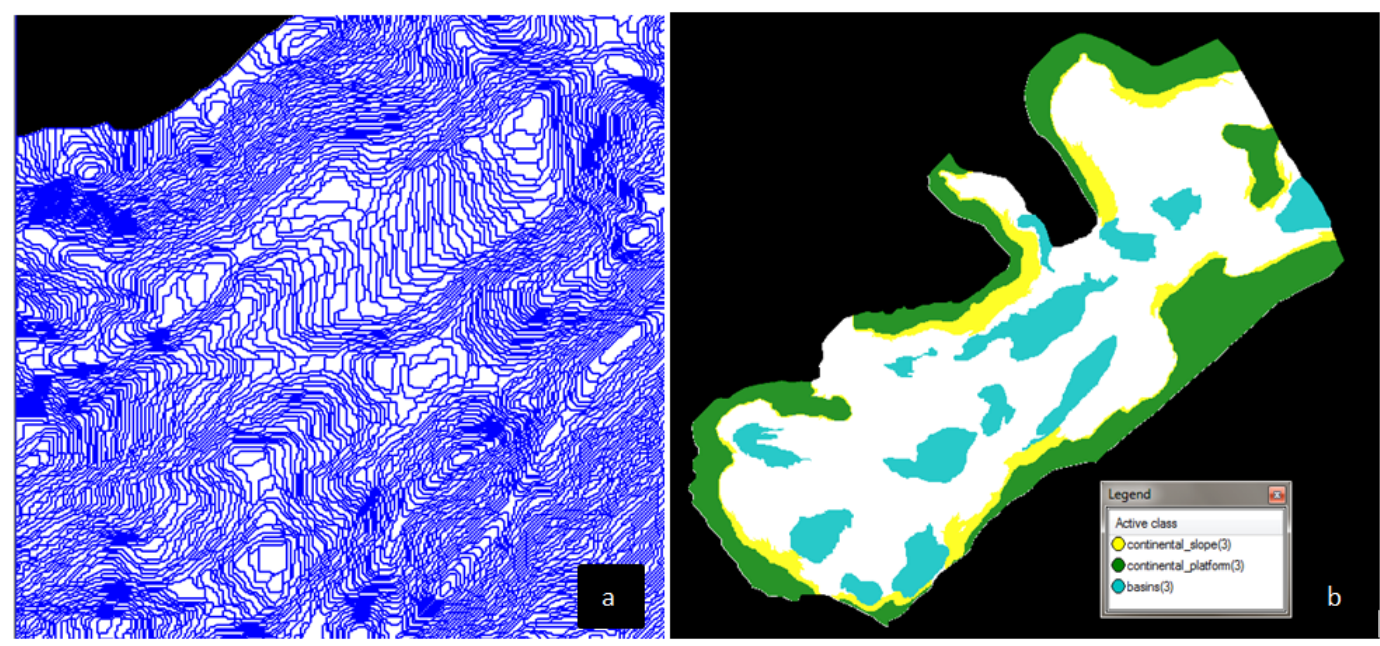

Figure 4 - a: A part of the segmentation result of level 3 with scale parameter 5, shape 0.1 , compactness 0.5, b: The classification result of level 3 .

\section{Level 4}

The aim of level 4 was the extraction of the fault surface(4). Fault surface, generally, is called the surface along which the two blocks move respectively to each other, so in this case is the area disclosed between discontinuity and the trace of the fault, while it is on the continental slope area. So, firstly, a new very fine segmentation, with scale 1 , shape 0.9 , and compactness 0.9 , was chosen in order to define the linear discontinuities and fault features. The segmentation result is almost pixel based, so a part of the whole area appears on Figure 5a. In level 4, five classes were classified in which continental platform(1) and continental slope(3) were projected from level 1 and level 3, respectively, while discontinuities(4), faults like(4) and fault surface(4) were defined at this level. The class faults like(4) is followed by "like" as the extracted faults were based on morphological 
criteria and not on the analysis of the seismic profiles. So, the criterion for the class faults like(4) is the maximum pixel value of profile curvature $\leq-10-5$, while the criterion for the discontinuities(4) class is the mean profile curvature $\geq 10-7$. The negative values of profile curvature indicate the concavity, and the positive values the convexity (Olaya, 2004). The discontinuities appear when there is a transition from mild to steep ground and that is a convex area, while the opposite, from steep to normal it is a concave ground which describes the fault-like class. The criterion for the classification of fault surface(4) class is based on the spatial relationship between the classes faults like(4) and discontinuities(4). Specifically, the fault surface(4) class has by definition a relative border with faultslike(4) and discontinuities(4). The result after this classification is shown on Figure 5 b, where the class fault surface(4) is illustrated with dark brown colour, the faults like(4) with light green and the discontinuities(4) with pink.
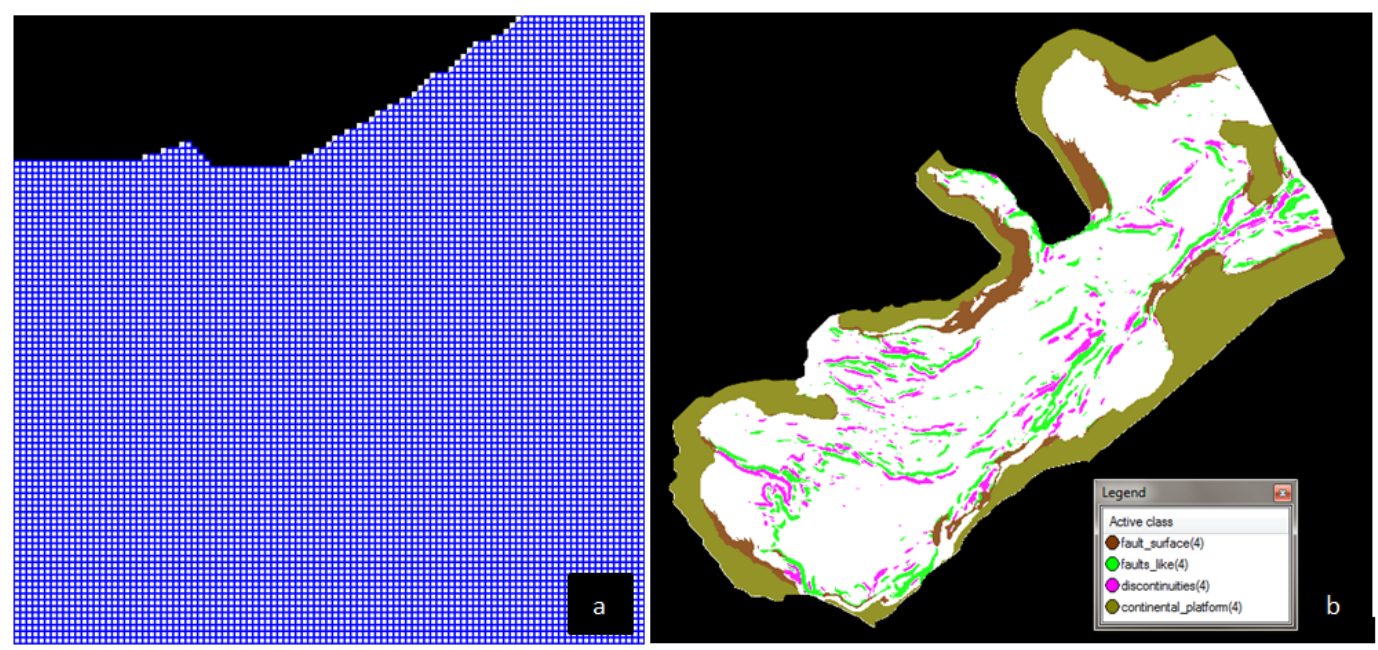

Figure 5 - a: A part of the segmentation result of level 4 with scale parameter 1 (shape 0.9 , compactness 0.9 ), b: The classification result of level 4.

\section{Discussion}

In order to evaluate the results of the landforms extracted through Object Based Image Analysis, a comparison took place with existing morphological and tectonic maps for this area. The classification result of basins(3) was compared with a morphotectonic sketch map (Papanikolaou et al., 2002), Figure 6a. In Figure 6b, the two basins, within orange circles, were probably misclassified, as they don't exist in Figure 6a. The four basins inside the rectangles were successfully classified as basins but comparing them with Figure 6a, they appear (in Figure 6b) to be merged with a neighboring basin. These divergences are explained below. The determination of the basins was made using the "percentile" parameter with a radius of 100. Even though, through a trial and error process, it turned out to be the most suitable for this case, the merging of small basins took place because of the relatively small distance between two basins in combination with the radius used, which contributed to the optimal detection of large basins. It is to be noticed that the most difficult landform to be extracted, in the whole area involved the basins. This occurred because all of the basins had their own characteristics and not common ones and thus it was difficult to find a single morphometric parameter to describe their morphometry. All of the basins did not have neither the same orientation, nor the same size etc. But, despite these difficulties, the advantage of OBIA was that all of the sub-basins of the North Aegean Basin were finally successfully identified. 


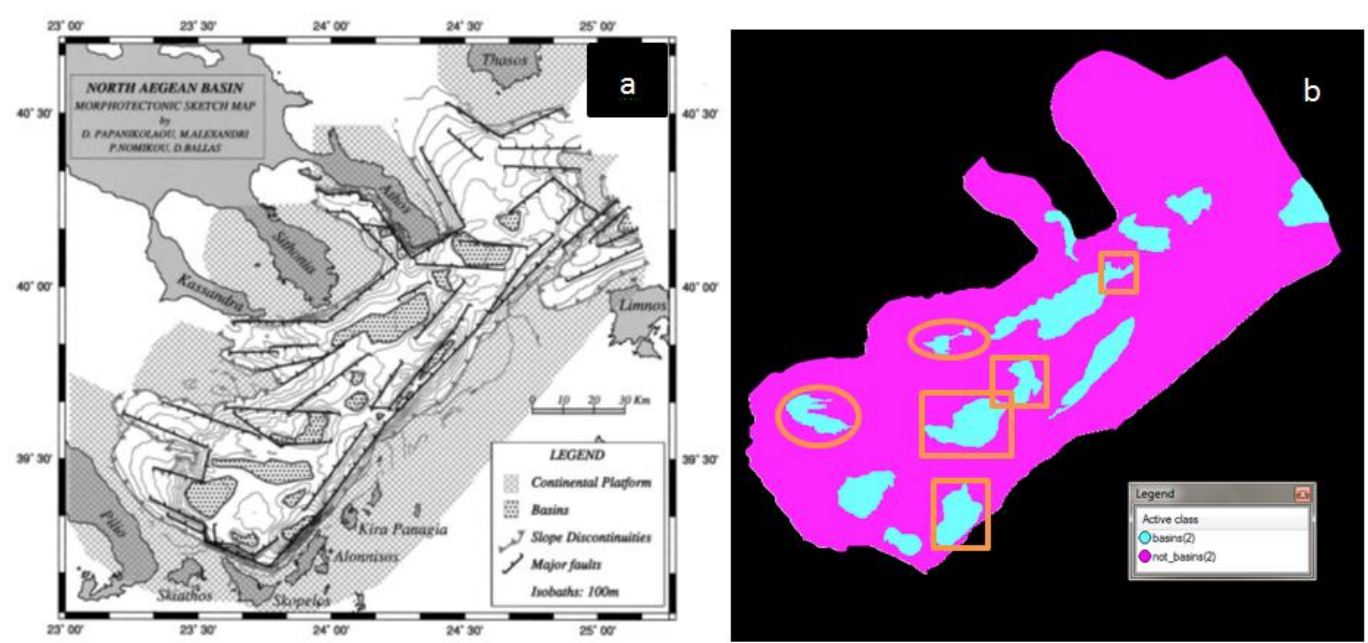

Figure 6 - a: The Morphotectonic sketch map illustrating the basins of N.Aegean (Papanikolaou et al., 2002), b: The classification result of level 2 illustrating the extracted basins.

To continue with, the classification result of continental platform (1) and continental slope (2) was compared to the bathymetric map (after Papanikolaou et al., 2002). In the bathymetric map, the classification of continental platform, continental slope and basinal area, as it is shown on the legend of Figure 7a, was based only on their different depths, while the continental platform and continental slope extracted through OBIA shown in Figure 7b, was based on the value of mean percentile.

Despite this, the continental platform was identified successfully comparing the green colour of Figure $7 \mathrm{~b}$ with the grey colour of Figure 7a. The continental slope (2) (yellow area in Figure 7b) which has been extracted based on the mean slope criterion, appears as a narrow strip comparing with the wide area of continental slope (white area) in Figure 7a. These divergences, occur because of the different approaches applied for determining the continental slope, something that was quite expected in this case, as the boundaries of the continental slope couldn't be exactly the same when the landform in one case (Figure 7a) is interpreted qualitatively and on the other is extracted quantitatively through geomorphometric parameters (Figure 7b).
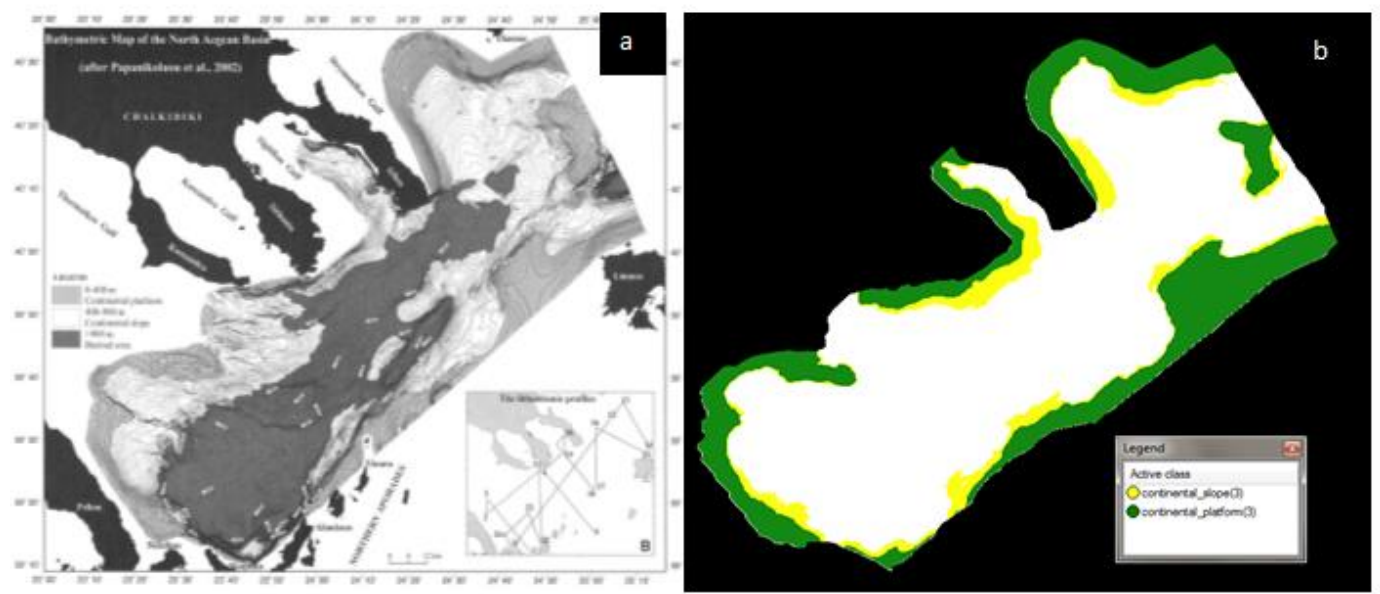

Figure 7 - a: The bathymetric map of the N.Aegean basin (after Papanikolaou et al., 2002), b: The classification result of level 3 illustrating the extracted continental slope and continental platform. 
Finally, the class faults like (4) is compared with faults resulted from the analysis of single channel airgun seismic profiles (Papanikolaou et al., 2006), (Figure 8).

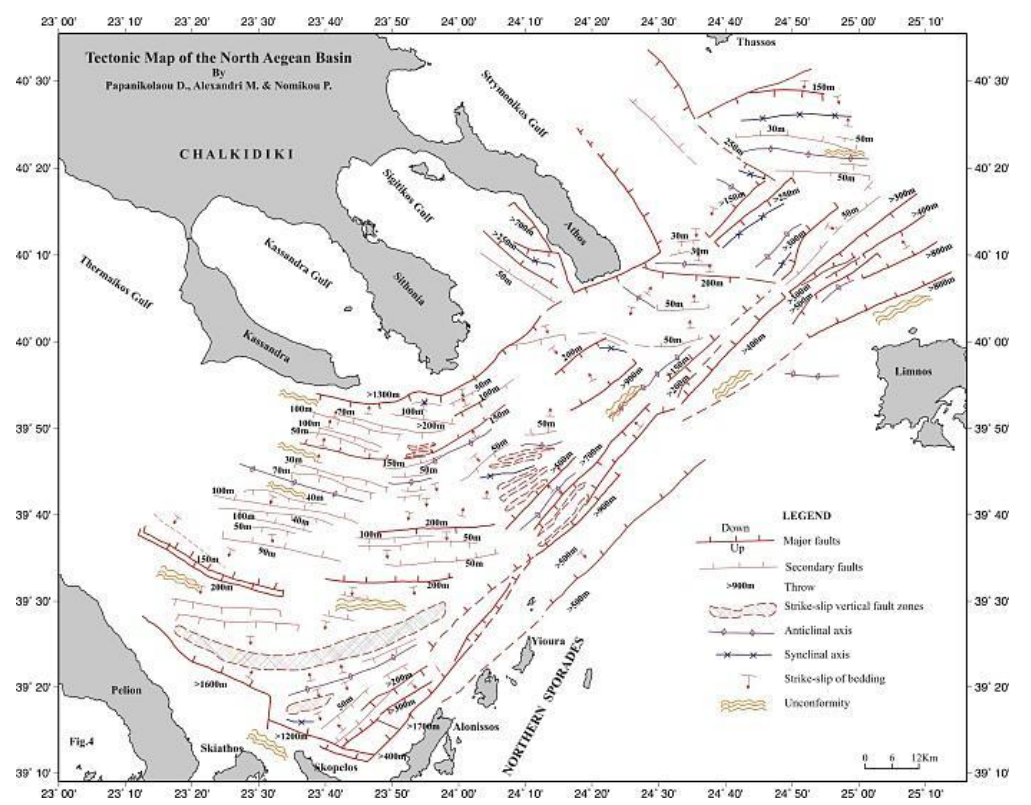

Figure 8 - The tectonic map of the North Aegean Basin (Papanikolaou, 2006).

In Figure 9 the faults digitized from the existing tectonic map of the North Aegean Basin (Papanikolaou et al., 2006) are shown in blue colour, while the class faults like (4) are shown in green and the discontinuities (4) in pink. In detail, the thin blue lines that represent the real existed faults of the seabed, they have a very good overlap in their majority, with the faults like (4) resulted from OBIA. Consequently, even though the class faults like (4) was automatically extracted based only on terrain morphology, there is a very good overlap close to $70 \%$ with the real existed faults of the seabed. So, it is confirmed that automatic methods, like Object Based Image Analysis (OBIA), has both advantages and disadvantages. The advantages are: i) its processing speed, ii) the existence of a multitude of alternative software classification algorithms, iii) clearly declared subjective rules. A drawback, however, is that the extracted results, depend on the quality of the digital terrain model employed. So the more detailed the digital terrain model is, the better the derived landforms would be.

\section{Conclusion}

Based on the comparison of the above maps, it is concluded that the developed OBIA approach was successful, as all of the sub-basins of the North Aegean Basin were identified, the continental platform and continental slope were correctly identified in the whole submarine area even though some divergences existed, due to the different approach of the reference map. Finally, the class faults like(4), despite the totally different nature of the approach, it was compared with the tectonic map and the morphologically extracted faults coincide quite well with the real faults The most important conclusion of this study is that using Object Based Image Analysis in swath data, permits the compilation of the morphotectonic sketch map of the North Aegean Basin based only on the morphological features without analyzing seismic profiles which sometimes are not existed. The OBIA approach is expected to be even more successful and precise on identifying geomorphological features with a better resolution DSEM, or with AUV data and it would be even more interesting in applying this approach to sidescan sonar images. 


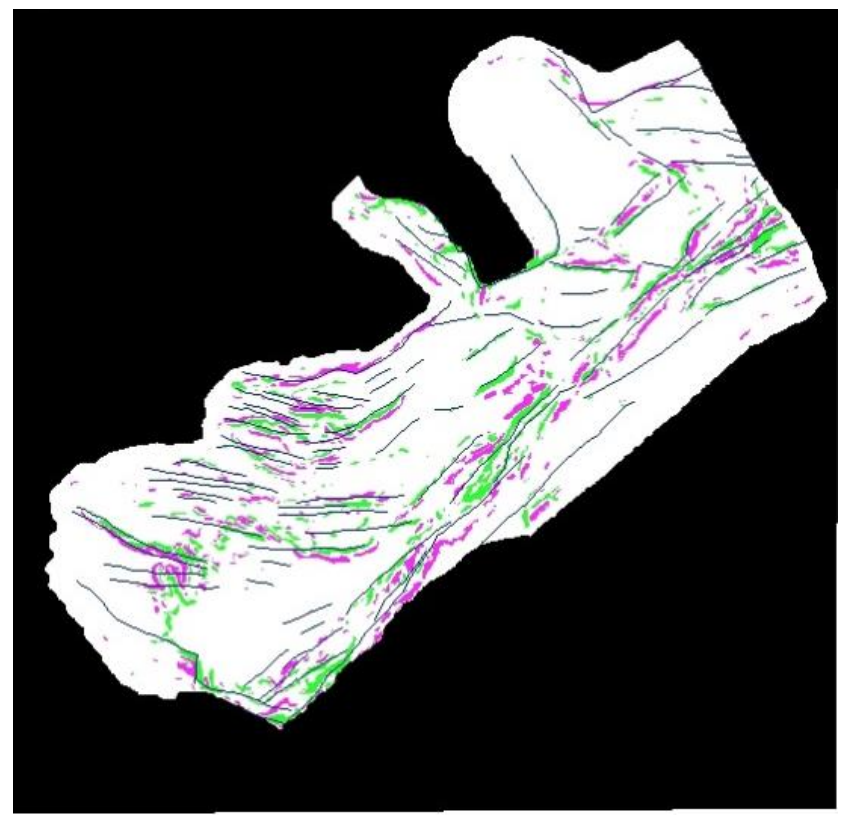

Figure 9 - The overlay of the digitized faults (thin blue lines) of the tectonic map on the faults like (4) (green lines) resulted from OBIA.

\section{Acknowledgements}

The Earthquake Planning and Protection Organization of Greece is acknowledged for financing the research project on the tectonic structure of the North Aegean Basin. The officers and the crew of the R/V Aegaeo are gratefully acknowledged for their effective contribution in acquiring the swath data. Prof. Argialas acknowledges the hint by Prof. George Veis (NTUA) on the need for automated approaches for determining faults and discontinuities in the Aegean seafloor. Matina Alexandri and Dionissis Ballas are gratefully acknowledged for their important and effective contribution during oceanographic cruise.

\section{References}

Angelier, J., Colletta, B., Chorowicz, J., Ortlieb, L. and Rangin, C., 1981. Fault tectonics of the Baja California Peninsula and the opening of the Sea of Cortez, Mexico, Journal of Structural Geology, 3(4), 347-357.

Angelier, J., 1979. Neotectonique de l'arc EŁgeen, Soc. Geol. Nord Publ. 3, 1-417.

Argialas, D. and Tzotsos, A., 2003. Geomorphological Feature Extraction from a Digital Elevation Model Through Fuzzy Knowledge-based Classification, in Remote Sensing for Environmental Monitoring, GIS Applications, and Geology II. M. Ehlers (Editor) Proceedings of SPIE International Conference on Remote Sensing, Vol. 4886, Agia Pelagia, Crete, 23-26 September 2002, 516-527

Argialas, D., 1995. Towards Structured Knowledge Models for Landform Representation, Zeitschrift für Geomorphologie N.F Suppl.-Bd., 101, 85-108, December, Berlin-Stuttgart.

Armijo, R., Meyer, B., Hubert, A. and Barka, A., 1999. Westward propagation of the North Anatolian Fault into the northern Aegean: Timing and kinematics, Geology, 27, 267-270.

Baatz, M. and Schäpe, A., 1999. Object-oriented and multi-scale image analysis in semantic networks. In 2nd international symposium: operationalization of remote sensing, 16(20), 7-13.

Brunn, H., 1976. L'arc concave zagro-taurique et les arcs convexes taurique et egeen; collision des arcs induits, Bulletin de la Société Géologique de France, 2, 553-567. 
Evans, I.S., 1972. General geomorphometry, derivatives of altitude and descriptive statistics, In: Chorley, R.J., eds., Spatial Analysis in Geomorphology, Harper \& Row, London, 17-90.

Jackson, J., 1994. Active tectonics of the Aegean region, Annual Review of Earth and Planetary Sciences, 22, 239-271.

Le Pichon, X. and Angelier, J., 1979. The Hellenic arc and trench system: a key to the neotectonic evolution of the Eastern Mediterranean area, Tectonophysics, 60, 1-42.

McKenzie, D., 1970. Plate tectonics in the Mediterranean Region, Nature, 226, 239-243.

McKenzie, D., 1972. Active tectonics in the Mediterranean region, Geophys. J. R. Astron. Soc., 30, 109-185.

Miliaresis, C. and Argialas, D., 1999. Segmentation of physiographic features from the global digital elevation model/GTOPO30, Computers \& Geosciences, 25(7), 715-728.

Olaya, V., 2004. A gentle introduction to SAGA GIS, The SAGA User Group e.V., Gottingen, Germany, 208 pp.

Papanikolaou, D., Alexandri, M. and Nomikou, P., 2006. Active faulting in the north Aegean basin, Geological Society of America Special Papers, 409, 189-209.

Papanikolaou, D., Alexandri, M., Nomikou, P. and Ballas, D., 2002. Morphotectonic structure of the western part of the North Aegean Basin based on swath bathymetry, Marine Geology, 190(1), 465-492.

Papazachos, B.C., 1980. Seismicity rates and long term earthquake prediction in the Aegean area, Quat. Geod., 3, 171-190.

Sengör, A., 1979. The North Anatolian transform fault: its age, offset and tectonic significance, Journal of the Geological Society, 136(3), 269-282.

Taymaz, T., Jackson, J. and McKenzie, D., 1991. Active tectonics of the North and Central Aegean Sea, Geophys. J. Int., 106, 433-490.

Trimble, 2011. eCognition ${ }^{\circledR}$ Developer 8.64. 1 User Guide.

Wilson, J. and Gallant, J., 2000. Terrain Analysis: Principles and Applications, Primary topographic attributes, 51-85, John Wiley \& Sons, New York.

Young, M., 1978. Terrain analysis: program documentation, Statistical characterisation of altitude matrices by computer: Report, 5 .

Zevenbergen, L. and Thorne, C., 1987. Quantitative analysis of land surface topography, Earth surface processes and landforms, 12(1), 47-56. 